\title{
Global Progressive Disease
}

National Cancer Institute

\section{Source}

National Cancer Institute. Global Progressive Disease. NCI Thesaurus. Code C159949.

Progressive disease in any skin, nodes, blood, or viscera category. 